\title{
Feminismo, discurso mediático y percepción social
}

\author{
Irene Pérez-Tirado'
}

Resumen: En 2017, la eclosión de las reivindicaciones feministas irrumpió con firmeza en el foco de los debates de la opinión pública. Ante esta realidad, este estudio considera que la comunicación del mensaje del movimiento feminista y la percepción social del mismo exigen mayor exploración, reflexión y clarificación. Los medios de comunicación (en adelante, MMCC) no solo proyectan, sino que construyen la realidad y modulan nuestras percepciones en torno a aspectos como el que aquí se estudia. Para analizar la incidencia de las reivindicaciones sociales, se aplica el Análisis Crítico del Discurso (en adelante, ACD) a un corpus seleccionado de artículos de prensa. Igualmente es preciso calibrar y analizar la percepción social que la ciudadanía tiene de los fenómenos que acontecen. El feminismo, a pesar de abogar por unos principios de evidente equidad y tras varios siglos de pedagogía, continúa resultando un término confuso y generador de sentimientos ambivalentes.

Palabras clave: Feminismo, medios de comunicación, discurso, percepción social.

Fecha de recepción: 9 de febrero de 2019.

Fecha de admisión definitiva: 8 de abril de 2019.

\section{Feminism, media discourse and social perception}

Abstract: In 2017, the emergence of feminist demands burst into the focus of public opinion debates. In the face of this reality,
Féminisme, discours médiatique et perception sociale

Résumé: En 2017, l'émergence des revendications féministes a fait irruption dans les débats d'opinion publique. Face à cette

' Universidad de Deusto. Estudiante pre-doctoral en DDHH. 
this study considers that the communication of the feminist movement's message and its social perception require greater exploration, reflection and clarification. The media not only project, but also construct reality and modulate our perceptions around aspects such as the one studied here. A Critical Discourse Analysis is applied to a selected corpus of press articles in order to analyze the incidence of social demands. It is also necessary to calibrate and analyze the social perception that citizens have of the phenomena that occur. Feminism, in spite of its advocacy of principles of evident equity and after several centuries of spreading its teachings, continues to be a confusing term that generates ambivalent feelings.

Key words: Feminism, media, discourse, social perception. réalité, cette étude considère que la communication du message du mouvement féministe et de sa perception sociale ont besoin d'une plus grande exploration, réflexion et clarification. Les médias non seulement projettent, mais construisent aussi la réalité et modulent nos perceptions autour $d^{\prime}$ aspects tels que celui étudié ici. Afin d'analyser l'incidence des revendications sociales, l'Analyse du Discours Critique est appliquée à un corpus sélectionné $d^{\prime}$ 'articles de presse. Il est également nécessaire de calibrer et d'analyser la perception sociale que les citoyens ont des phénomènes qui se produisent. Le féminisme, malgré ses revendications des principes d'équité évidente et après plusieurs siècles de diffusion de ses enseignements, continue d'être un terme déroutant qui génère des sentiments ambivalents.

Mots clé: Féminisme, médias, discours, perception sociale.

\section{Introducción}

En 2017, «Feminismo» fue el término elegido por los editores del diccionario estadounidense Merriam-Webster, como la palabra del año. La eclosión de las reivindicaciones feministas ha irrumpido con firmeza en el foco de los debates de la opinión pública.

En el panorama internacional, la masiva revelación y denuncia de abusos golpeó el corazón del mundo cinematográfico en Hollywood y se gestó el movimiento de denuncia \#metoo. A raíz de las acusaciones de abusos sexuales contra el productor Harvey Weinstein, se unieron a la reivindicación más personas, en su mayoría mujeres, con el fin de visibilizar la magnitud de este problema. El simbólico hashtag (\#metoo) fue la iniciativa de sororidad que compartieron todas las personas denunciantes de estos abusos.

En el ámbito estatal, la fuerza con la que el $8 \mathrm{M}$ (8 de marzo de 2018) recorrió las calles, sentenció un hito histórico. Con solo un antecedente de similares caracterís- 
ticas, este tuvo lugar en Islandia en 1975, cuando el $90 \%$ de las mujeres hicieron huelga para manifestarse en contra de la desigualdad de género, paralizando el país. Aquí, el 8M también gozó de un apoyo cívico masivo y se vivió como una iniciativa vibrante en primera línea de la atención mediática. Este episodio, y otros, como el caso de "La Manada" (nombre con el que se conoce el suceso de violencia sexual que tuvo lugar en Pamplona en julio de 2016), han avivado el ímpetu de las protestas feministas.

La revivificación del propio concepto de «feminismo» también se vislumbra en datos. Consultando Google Trends se puede apreciar que (1) las búsquedas relativas a este término aumentaron considerablemente durante el mes de marzo de 2018, alcanzando su pico entre los días 4-10 de dicho mes.

Por otro lado, en la comparativa entre regiones, País Vasco y Madrid son los territorios desde los que se realizó un mayor número de consultas (2).

\section{FIGURA I. Resultados búsqueda concepto “feminismo” (I) (2)}

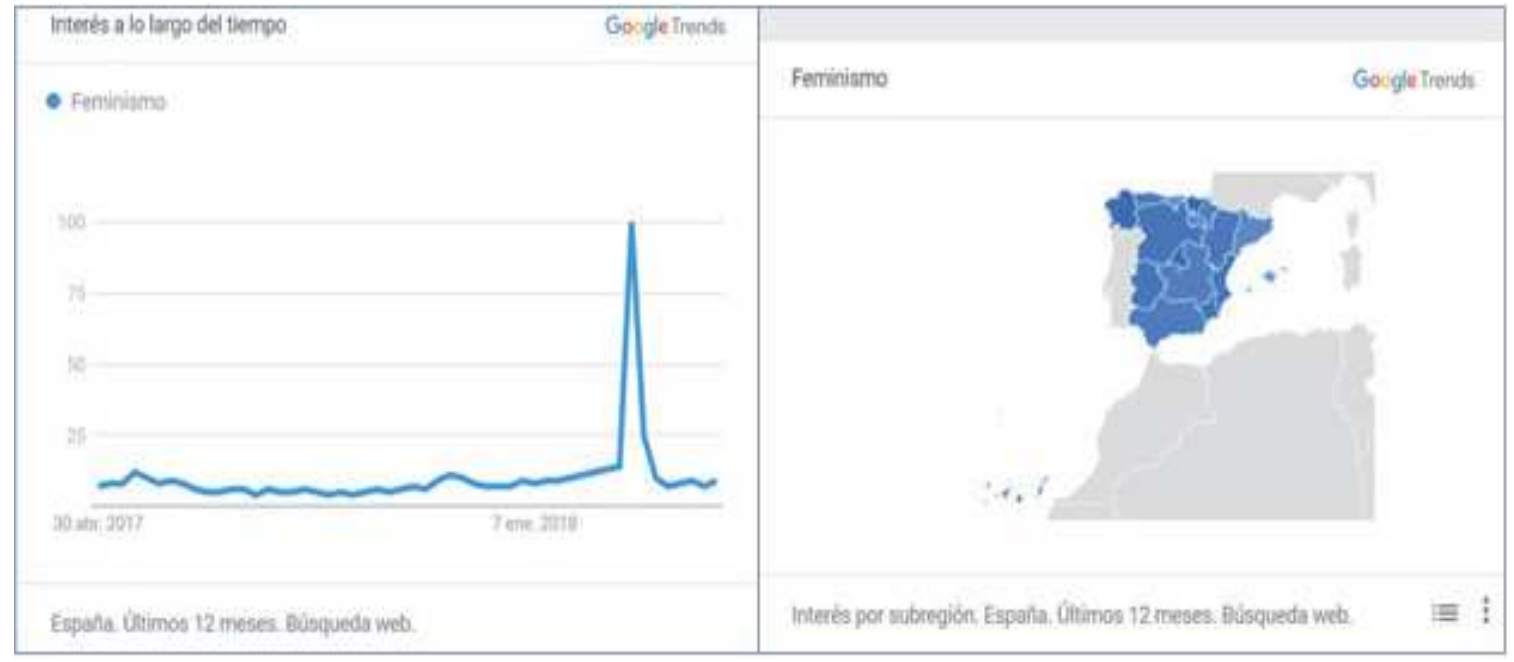

Fuente: Google Trends.

Así pues, y a modo de introducción, esta tesis se construyó alrededor de una pregunta concreta:

¿Cómo se construye el discurso mediático en torno al feminismo y cómo está percibiendo la sociedad este fenómeno social? 
Comenzando por dar una definición teórica del término «feminismo», este queda delimitado por Victoria Sau en el Diccionario ideológico feminista como:

Movimiento social y político que se inicia formalmente a finales del siglo XVIII y que supone la toma de conciencia de las mujeres como grupo o colectivo humano, de la opresión, dominación y explotación de que han sido y son objeto por parte del colectivo de varones en el seno de patriarcado bajo sus distintas fases históricas de modelo de producción, lo cual las mueve a la acción para la liberación de su sexo con todas las transformaciones de la sociedad que aquélla requiera (p. 121).

El feminismo surgió hace tres siglos y como dice Amelia Valcárcel (1991), es un «hijo no querido de la llustración». Desde aquel disruptivo episodio de la historia, de revolución política, cultural e intelectual, y hasta nuestros días, se comenzaron a formular preguntas como ¿por qué las mujeres están discriminadas?, ¿̇cuál es el origen de esta exclusión? y ¿̇cómo se puede combatir? Ya fraguado como movimiento social, este bebe de un discurso político que se fundamenta en la justicia social. Pero a pesar de abogar por unos principios de evidente equidad $y$ tras varios siglos de pedagogía feminista, este término sigue resultando confuso y generador de sentimientos ambivalentes.

Parte de la responsabilidad de esta realidad simbólica ambigua construida alrededor del feminismo recae en los MMCC. En el seno de una sociedad supuestamente hiperinformada, estos tienen un rol fundamental en la construcción simbólica de la realidad y no son pocos los estudios que advierten que la exposición al discurso mediático ha podido ser un factor crucial en la negativa representación e interiorización del mismo (Zucker, 2004).

Los MMCC no solo son productores/reproductores ideológicos, sino que además influyen en la legitimación social de la realidad.

Es por ello que aplicar el ACD a algunos textos sobre el movimiento feminista publicados en prensa puede resultar muy esclarecedor. Esta metodología basada en la teoría de Teun A. van Dijk, presupone que los discursos periodísticos no son objetivos porque siempre hay una ideología implícita en los mismos. Por tanto, aplicando esta herramienta de análisis, podría vislumbrarse la tendencia ideológica e influencia del contexto.

Con el propósito de contribuir al paradigma socio-cognitivo vinculado al feminismo, resulta necesario por tanto explorar la transformación social que el movimiento social impulsa desde el discurso y el lenguaje, ya que será a partir del mensaje recibido desde donde construiremos el imaginario colectivo que gira en torno al movimiento feminista. 
En estas circunstancias, la sociedad también es responsable y solo construyendo una ciudadanía crítica se puede conseguir consolidar una opinión pública coherente y responsable.

Ante esta situación, es preciso calibrar y analizar la percepción social que la ciudadanía tiene de los fenómenos que acontecen. Los estudios de percepción social donde se "monitoriza" cómo se está entendiendo el cambio o cuáles son las preocupaciones y retos a futuro resultan herramientas de consulta de gran relevancia. En este punto se pretenderá comprender qué conocimientos poseemos sobre el movimiento feminista, qué sentimientos nos provoca y qué actitudes mostramos ante ello.

En este ejercicio de análisis, será esencial tener presente la realidad política/económica/social del momento, así como las peculiaridades propias de un contexto de incertidumbre en este resurgido ciclo de protesta feminista. Este análisis sociológico conecta con los intereses de la Unión Europea ya que una de las prioridades de la estrategia «Horizonte 2020» recae en financiar proyectos de investigación e innovación dedicados a retos de calado social. En relación con ello, uno de los objetivos específicos del programa se define como Europa en un mundo cambiante: Sociedades inclusivas, innovadoras y reflexivas y es aquí donde encajaría el debate de esta investigación. La brecha salarial, la conciliación familiar, la violencia de género o la educación son algunas de las luchas reivindicadas desde el feminismo que repuntan con brío en la actualidad. Incuestionablemente, estas reclamaciones constituyen retos de la propia UE que como ente demanda nuevas ideas, estrategias de gobernanza e innovación social para darles respuesta en el seno de una crisis estructural, social y política de carácter global.

Ante este general esbozo de la justificación de la propuesta de estudio, queda patente la relevancia de este movimiento social y el interés por seguir avanzando en los estudios del mismo. Pero si se me permite aludir a cuestiones personales para complementar la motivación que me lleva a defender este estudio, debo señalar a mi etapa de formación universitaria en la que no pude detectar a ningún/a docente que, en carreras de cáliz tan social como son Periodismo o Ciencias Políticas, nos hablase de feminismo. Del mismo modo en mis compañeros/as de generación también pude distinguir cierta ausencia de sensibilidad feminista.

Esto me anima a seguir trabajando en pos de la visibilidad y la comprensión de uno de los fenómenos sociales más importantes de los últimos siglos.

Tras lo anteriormente expuesto, se puede concluir que este estudio considera que la comunicación del mensaje del movimiento feminista y la percepción social del 
mismo exigen mayor exploración, reflexión y clarificación. El primer objeto de análisis se centrará así pues en el tratamiento que exhibió la prensa en torno a este fenómeno social. Posteriormente, se tratará de descubrir cuál es el modo en el que la gente entiende la filosofía del movimiento y cómo están viviendo este momento. Así mismo, resulta interesante indagar en la actualidad de este fenómeno social acotado en el terreno de la Comunidad Autónoma de Euskadi (en adelante, CAE) ya que la idiosincrasia propia de este territorio podría arrojar resultados diversos a los obtenidos en otros lugares del mundo.

El ya citado florecido feminismo quedó materializado en una jornada como la del 8 de marzo en la que el nivel de participación fue desbordante, el debate social generalizado y la sororidad femenina ilusionante. Según datos facilitados por los sindicatos, el paro habría sido secundado por 5,3 millones de trabajadoras y trabajadores. Así mismo, las calles de, no solo las ciudades más importantes del país, sino también de pueblos en los que la movilización feminista no tenía precedentes, se llenaron de manifestantes.

Ante lo que fue un irrebatible momento histórico hace falta ahora identificar si también es un esperanzador punto de inflexión con respuestas a preguntas como estas: $\dot{i}$ Es un año diferente? $\dot{\partial}$ Es el año de las mujeres? $\dot{2}$ Realmente estamos ante

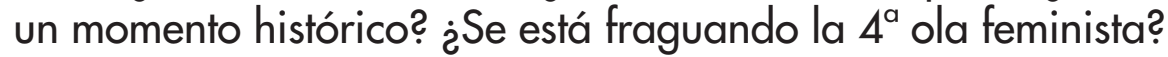

En este contexto, esta investigación de metodología mixta tiene el propósito de describir, teorizar y mejorar el alcance del mensaje del movimiento feminista como sujeto de comunicación.

\section{Revisión literaria}

La realidad actual del panorama sociopolítico parece estar experimentando una revivificación del interés por el feminismo. Una cuestionada " $4^{\circ}$ » ola para ciertas/ os teóricas/os que se ha fraguado en los medios sociales digitales (Hasmath, 2014; Phillips \& Cree, 2014).

Los picos de reivindicación no se dan de manera aleatoria, sino que responden a ciertos periodos históricos. Se trata de los llamados ciclos de protesta, los cuales en el devenir natural de los movimientos sociales alternan con periodos de menor visibilidad, pero igual relevancia. Son lo que Alberto Melucci (1994) acuñó como períodos de latencia, en los que el conflicto y las reivindicaciones, lejos de estar apagados, se mantienen silenciados. 
Conectando esta realidad en el desarrollo de los fenómenos sociales con el feminismo, Rossi (1982) afirmó que en el movimiento se da un ciclo generacional de disminuida visibilidad de su acción política ("Quiet periods"), que separa cada ola feminista por 50 años, o dos generaciones.

\section{I. Feminismo}

Tal y como defiende Freedman (2001), resulta complejo describir qué significa el movimiento feminista ya que no se da una definición compartida del mismo. A pesar de ello, a continuación, se apuntan algunas descripciones para aterrizar este fenómeno social. Bell Hooks (2000), señala: "simplemente, el feminismo es un movimiento para acabar con el sexismo, la explotación sexista y la opresión" (p. 1).

Recurriendo a las palabras de Chapman (1914), este decía de la ideología feminista, pretender "una rebelión a escala mundial contra todas las barreras artificiales que las leyes y las tradiciones interponen entre las mujeres y la libertad humana" (citado en Cacace, 2006, p. 28)

En relación con esto, cabe puntualizar que las ideologías son las ideas sociales que comparte un determinado grupo social (Van Dijk, 2003) y, por tanto, representan principios ocultos de cognición social, es decir, un esquema mental definido por ciertos intereses. En lo referente al feminismo, este pertenece a un tipo de ideología positiva y no dominante.

Ya habiendo dado algunas definiciones y puntualizaciones de este fenómeno social, el feminismo es uno de los movimientos sociales e ideológicos más influyente de los últimos siglos (Facio, 1999; Sendón de León, 2000).

Así mismo, en el devenir de estos años de lucha feminista se ha hecho patente que como decía Kate Millet (1970) lo personal es político, por lo que la esfera privada ha quedado ligada a una necesaria reivindicación pública basada en la justicia social.

Pero a pesar de que las pretensiones del movimiento han pivotado alrededor este principio de justicia, este ha padecido desde sus orígenes un estigmatizado imaginario social. Durante la mayor parte de su historia el feminismo ha tenido que lidiar con una negativa representación que ha calado en el imaginario colectivo de la sociedad. 
A consecuencia de todo ello, el rechazo social a la identidad feminista ha resultado algo histórico y los estereotipos negativos han estado históricamente vinculados con el movimiento.

\subsection{Medios de comunicación}

En torno al feminismo y a las mujeres (o personas) que militan en este movimiento se ha fraguado un negativo estereotipo cultural y es aquí donde, según algunos autores, los MMCC han tenido una responsabilidad destacada (Rhode, 1995). Como señala Douglas (1994) en los 70s la palabra feminismo se convirtió en una «dirty word» (palabra-sucia) señalando a las feministas como personas desviadas, «man-hating» (odia-hombres) y radicales que amenazaban el orden establecido (p.165). Apoyando esta premisa, Lull, Mulac y Rosen (1983) demostraron en su estudio que las personas que se identificaban con los principios del movimiento feminista veían menos la tv que los sujetos que no lo hacían.

En un artículo publicado por Zucker (2004), la autora aseguraba que el acercamiento al feminismo a través de la educación, las relaciones o luchas personales son condiciones favorables para la identidad feminista, mientras que la exposición a los MMCC y la asociación del feminismo con el extremismo son barreras a la identificación con este movimiento social.

La investigación de Faludi (1991) también asegura que la esfera mediática ha apoyado la reacción antifeminista. Del mismo modo, en un intento disuasorio, estos también han dado a entender que "no es necesaria más acción feminista" (Schneider 1988, p. 11)

A este respecto Esteban Morán Torres considera que: "No cabe la neutralidad, el tratamiento aséptico de la noticia en el periodismo de opinión. Para bien o para mal, el comentarista, el editorialista, el crítico y el columnista están dirigiendo al público en una dirección determinada" (1998, p. 11). También Castells (2009) hace alusión al poder intrínseco en los medios los cuales son el espacio donde se fragua la representación del poder.

Las autoras de El sexo de la noticia defienden que: "la elección de un titular, de una ilustración que acompaña un texto, de una palabra, del adjetivo usado en la descripción o calificación de una persona, del estilo y de la forma como se hable de quien protagoniza los hechos, también forman parte de esta producción social que es siempre dinámica y cambiante" $(2000$, p. 4). 
Ya férreamente reconocido el poder del discurso mediático, este también es capaz de difundir la filosofía del movimiento feminista a la sociedad. Llevar a cabo este ejercicio supone defender los cambios sociales que exige el feminismo para construir una sociedad más igualitaria con respecto al género (Boix, 2002).

Con lo anteriormente expuesto, y través de un $A C D$, se pretenderán identificar e interpretar los mensajes relativos al feminismo. El ACD ofrece minuciosos análisis de las estructuras y estrategias del texto y de la relación de este con el contexto social y político en el que ha sido producido. Este tipo de estudios ayuda a esclarecer la orientación argumentativa intrínseca al texto cuya intencionalidad es procurar la aceptación o el rechazo de una representación social concreta. Y es que como ya postularon autores/as como el filósofo Foucault (1983) o la teórica feminista Butler (1990), es fundamental tener presente la importancia en el uso del lenguaje.

Así pues, entendemos que en un tiempo de transformación como el actual, en el que el debate feminista está bajo el foco mediático, es esencial analizar los discursos que recibimos.

En algunos de ellos se podrán entrever intenciones de perpetuar el orden imperante, de resistir ante lo que se percibe como una amenaza feminista.

Así pues, y como defienden Van den Brink y Benschop (2014) es necesario detectar las estrategias de quienes pretenden mantener el poder de inclusión y exclusión, ya que las desigualdades estructurales de género persistirán siempre y cuando sigan manifestándose estas resistencias.

A propósito de esa reflexión, resulta interesante la cita de Rosa Montero: "Cada cambio importante origina una respuesta retrógrada; cada avance una añoranza de involución" (Montero, 2018, p. 80).

\subsection{Percepción social}

Pero tan necesario resulta entender la intencionalidad de los discursos en el universo simbólico de la audiencia como comprender cuál es el modo en el que la sociedad está percibiendo ese cambio, quizá histórico.

Desde hace décadas, se han configurado varias escalas para medir las actitudes e identidad feministas. Por aportar unas pinceladas de las conclusiones extraídas en algunos de estos estudios, una de las afirmaciones más compartidas sería que las 
reacciones antifeministas estarían en parte causadas por lo que ellas denominan la justificación del sistema (Yeung, Kay y Peach, 2014).

En relación con esto, resulta relevante señalar que la identidad social se forma en función de la pertenencia o no a diversos grupos. Como Tajfel y Turner (1989) argumentaban, las personas, en su intención por formar parte del grupo, procurarán tener identidad social positiva y no negativa.

Haciendo alusión a las investigaciones de percepción social del feminismo consultadas por el momento, se puede destacar que, a pesar de llevar más de 80 años estudiándose esta temática, en el contexto español han sido notablemente escasas. La práctica totalidad de los estudios se han llevado a cabo en EEUU existiendo pocas referencias relevantes fuera de este espacio. Así mismo, entre los antecedentes impera la metodología cuantitativa en formato cuestionario por su mayor facilidad de aplicación. No fue hasta 2003 cuando Pamela Aronson se acercó al estudio del feminismo de forma exclusivamente cualitativa. Otro aspecto a tener en cuenta es que muchas escalas han sido aplicadas a muestras de participantes sesgados, centrándose especialmente en mujeres de perfil universitario como en el estudio de Zucker (2004).

Se puede concluir por tanto que lo fenómenos y cambios que irrumpen en el panorama social son definidos, reproducidos, evaluados y sometidos a juicio en textos y discursos orales que serán transmitidos a la opinión pública. Es por ello que la percepción social de un determinado fenómeno y, por ende, las actitudes que se desarrollan hacia el mismo, están influenciadas por el mensaje que reproducen los MMCC y la realidad simbólica que construyen. $Y$ es que en un contexto como el actual, en el que según Carter (2012) las identidades (individuales y colectivas) son flexibles, cambiantes, fluidas o, cómo calificaría Bauman (1999) líquidas, este estudio resulta de especial interés. 


\section{Objetivos e hipótesis}

\section{I. Objetivos generales y específicos}

Los objetivos generales y específicos que esta investigación se propone alcanzar son:

1. Analizar de manera crítica el discurso mediático transmitido por los medios informativos impresos en torno al feminismo.

a) Realizar un análisis cuantitativo contrastivo de prensa.

b) Analizar en profundidad el tratamiento del feminismo en prensa (léxico valorativo, tendencia ideológica, prejuicios, etc.)

2. Conocer cuál es la percepción social de la población de la CAE sobre el movimiento feminista, y qué opina sobre cómo reflejan los medios informativos impresos este fenómeno.

a) Conocer el consumo de medios de la población de la CAE.

b) Sondear qué conocimientos posee, qué sentimientos les provoca y qué actitudes muestra la sociedad vasca hacia el feminismo.

c) Analizar la percepción que tiene la sociedad vasca del tratamiento del movimiento feminista en prensa.

\subsection{Hipótesis}

Como ya se ha señalado anteriormente, la tesis despertó en torno a esta pregunta general:

¿Cómo se construye el discurso mediático en torno al feminismo y cómo está percibiendo la sociedad este fenómeno social?

En base a ello, las hipótesis que vertebran este estudio serían:

- La respuesta de los MMCC en su discurso mediático hacia los avances del feminismo muestra ciertas resistencias y oposición al cambio.

- La percepción social del momento actual del feminismo es confusa y la adhesión de la etiqueta feminista sigue resultando cuestionada. 


\section{Metodología}

Para alcanzar los objetivos indicados se establecerán 5 fases en las que combinaremos diversos métodos de investigación para dar respuesta a nuestras cuestiones iniciales.

Comenzando por una fotografía de la situación actual en la comunicación/percepción del mensaje feminista, se realizará seguidamente un estudio de caso del discurso periodístico. Posteriormente se tratará de ahondar en la percepción social del feminismo y así construir finalmente un diagnóstico que monitorice como se está emitiendo/recibiendo el mensaje.

En definitiva, una simbiosis metodológica que aúne revisión documental, junto con revisión empírica (ACD, cuestionario, entrevistas y grupo de discusión) para confluir en una argumentación lo más teorizada posible en torno a este fenómeno social en constante trasformación.

A continuación, se desarrollan más detalladamente los objetivos, la metodología y los resultados previstos en cada una de las etapas planificadas.

\section{I. Fase I. Revisión documental}

En primer lugar, nos aproximaremos al Estado de la cuestión de nuestro tema sometido a análisis mediante la pertinente y rigurosa revisión bibliográfica.

En esta recuperación documental exploraremos determinados conceptos clave a los que nos aproximaremos teóricamente. Así mismo, recopilaremos los estudios más relevantes sobre feminismo y discurso mediático, así como aquellos que de una forma innovadora y eficaz hayan llevado a cabo análisis de percepción social de este fenómeno social.

\subsection{Fase 2. Revisión empírica (I): ACD (Discurso Mediático)}

En esta etapa se intentará analizar, de manera crítica, el discurso mediático producido en la prensa más consumida en la CAE. Para ello se seleccionará un corpus compuesto por escritos del género de opinión (editoriales, artículos de opinión, viñetas y cartas al director) publicados durante los meses de enero, febrero y marzo de 2018. Los periódicos a consultar serán los de mayor tirada en el territorio 
según el Estudio General de Medios, 2018, comprendiendo El Correo, Deia, Gara y las tiradas de El País y El Mundo en la CAE. Esta muestra de publicaciones se examinará siguiendo el $A C D$, metodología basada en la teoría de Teun A. van Dijk.

\subsection{Fase 3. Revisión empírica (II): Cuestionario (Percepción Social)}

Una vez esbozado el modo en el que la prensa construye su discurso mediático se pondrá el foco en cómo, la sociedad vasca, percibe el feminismo.

La estrategia de esta fase está por ser definida pero quizá se dé la posibilidad de lanzar nuestras cuestiones dentro del Deusto barómetro llevado a cabo por el Equipo de Deusto Valores Sociales. De no ser posible, se estudiarán otros modos de aplicar esta metodología. En cualquier caso, la muestra formada por (xOO) individuos sería estadísticamente representativa y configuraría una selección aleatoria de hogares y cuotas de sexo y edad de la población residente en Euskadi. Las variables sometidas a análisis podrían estructurarse en 3 bloques temáticos básicos:

a) Conocimiento sobre el movimiento feminista (valores/ objetivos)

b) Percepción del activismo feminista (beneficios/ inconvenientes, etc.)

c) Participación en el movimiento o en la filosofía del mismo

\subsection{Fase 4. Revisión empírica (III): Entrevistas y Grupos de discusión}

Tras esta aproximación masiva al conocimiento de la percepción social, está previsto complementar esta metodología cuantitativa con una versión cualitativa de respuestas que dote de mayor profundidad a la comprensión de esta realidad.

La intencionalidad de incluir esta metodología es analizar en mayor profundidad los discursos de las personas, así como obtener más información con la que interpretar los datos obtenidos en el cuestionario.

Para ello se realizarán algunas entrevistas en profundidad, así como grupo de discusión:

\section{a) Entrevistas en profundidad}

En un primer balance hemos estimado que (6) entrevistas en profundidad de carácter semiestructurado serán suficientes. Estas/os informantes serán figuras 
clave, principalmente personal académico, profesionales de los MMCC y personal político o institucional.

\section{b) Grupo de discusión}

A continuación, y con el objetivo de contrastar e interpretar los resultados obtenidos anteriormente se tiene previsto realizar (1) grupo de discusión. La dinámica grupal seguirá las dimensiones tratadas en el guion temático de la encuesta y el grupo estará configurado en paridad de género. Así mismo, la sesión será grabada en audio y se transcribirá literalmente para posteriormente ser interpretada.

\subsection{Fin de proyecto}

Por último, se llevará a cabo un ejercicio final de reflexión de las ideas generadas a lo largo del proyecto. En todo el proceso de recopilación y manipulación de la información obtenida se tendrán en cuenta las recomendaciones sugeridas por Strauss y Corbin (1990, p. 17) los cuales consideran que, para analizar críticamente una situación, se debe estar dotado de sensibilidad social y teórica, defenderse desde una distancia analítica y, a su vez, recurrir a su experiencia y conocimiento teórico.

A priori, la ambición de este proyecto es, tal y como señalaba la ilustración, articular una simbiosis metodológica que aúne revisión literaria y revisión empírica para confluir en una argumentación lo más teorizada posible. La investigación será de carácter mixto, en una pretensión de utilizar las fortalezas de los métodos cualitativos y cuantitativos en combinación y, así, minimizando sus debilidades.

Así pues, se pretende aglutinar datos, indicadores, estadísticas, narrativas, discursos, etc. y con ello realizar una lectura ética de esta realidad. Posteriormente, apoyándonos en lo obtenido en el trabajo de campo y, siguiendo los preceptos de la Teoría Fundamentada (Strauss y Corbin 1990), se tratarán de construir teorías, hipótesis, conceptos y proposiciones, resultando esta combinación una metodología idónea para explorar en profundidad un determinado fenómeno social como es el feminismo. Nuestro propósito será por tanto entender e interpretar una determinada realidad, una realidad compleja, pero además de algún modo cuantificarla y por tanto pretenderemos, no solo descubrir, sino además construir conocimiento.

El siguiente cuadro recoge una estimación de los trabajos previstos en cada una de las fases. 
FIGURA 2. Resumen fases previstas

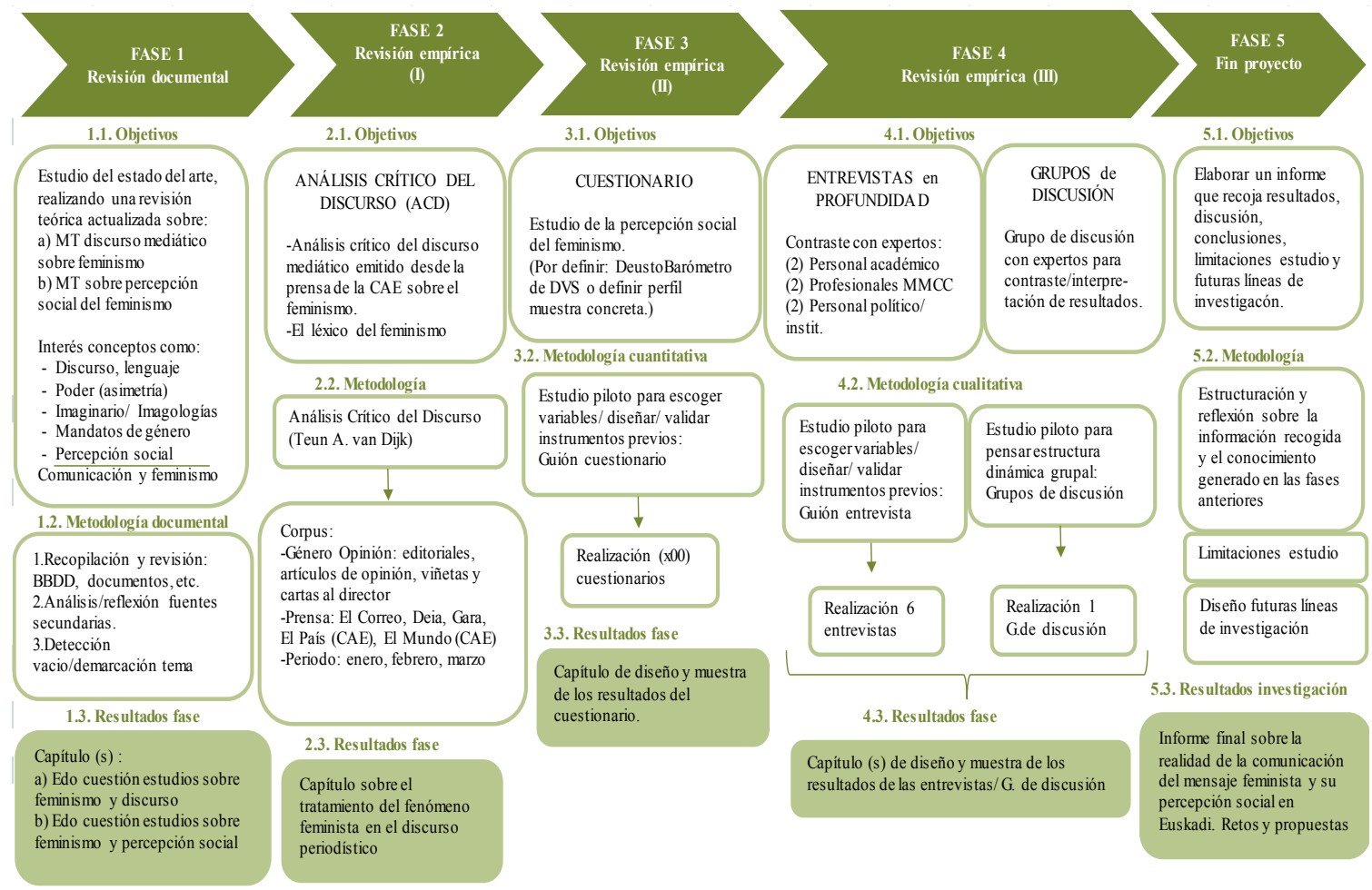

Fuente: elaboración propia.

\section{Resultados esperados}

Esta investigación se enmarca en el proyecto de una tesis doctoral y por tanto los resultados de cada uno de los tres estudios planteados irán dando luz a las cuestiones apuntadas al inicio.

Con la breve revisión de literatura presentada, la pertinente exposición de los objetivos e hipótesis y el trazado de la simbiosis metodológica diseñada se ha pretendido situar el fenómeno social a estudio, el feminismo, y dar a conocer las inquietudes que surgen alrededor de esta investigación.

No se trata por tanto de una presentación de respuestas (o resultados) sino más bien de preguntas, las cuales tendrán una doble misión de guía y soporte del resto de la investigación. Es por ello que consideraba esencial compartirlo con especialistas en la materia como los/las asistentes a este encuentro donde cualquier sugerencia o recomendación será bien agradecida. 
A continuación, se presentará un ejemplo de los avances conseguidos por el momento en el primero de los estudios de esta investigación.

\section{I. Ejemplo de Análisis del Discurso mediático}

En lo referente al tratamiento del Movimiento Feminista por parte de los MMCC se puede intuir el cambio en un doble sentido: cuantitativo y cualitativo.

La atención mediática ha centrado el foco en el feminismo al otorgarle, en el último año, una mayor cobertura a los asuntos vinculados con este fenómeno social. El feminismo resulta noticiable quedando consolidado en la agenda mediática y por ende en las rutinas productivas de los/las periodistas. Ante este repunte de visibilidad del movimiento, este cobrará mayor relevancia para la opinión pública quedando evidenciado el efecto "agenda setting».

En cuanto al análisis cualitativo, el ACD revelará el modo en el que los profesionales que en esta esfera ocupan el discurso mediático (élite), trata el feminismo para lo cual se escogerán ciertas estrategias (o premisas). El corpus de artículos de opinión seleccionado pasará por el tamiz de dichas estrategias para entender qué se dice sobre el feminismo y cómo se dice.

Existe, por tanto, consenso al señalar que el 2017 supuso un año de punto de inflexión en el repunte del tratamiento mediático de esta lucha social. Como se ha comentado con anterioridad fueron varios los casos «key event» o caso índice) que despertaron dicho cambio.

Además, el periodismo de opinión es un espacio de exposición abierta de diferentes posturas ideológicas por medio del instrumento lingüístico y ante ello se intentará vislumbrar si se muestra resistencia o apoyo al cambio.

Así mismo, en el análisis a este corpus de artículos sería interesante revelar el género de los/las periodistas que tienen su autoría. Según un reciente estudio llevado a cabo en enero de 2018 por la consultora de Comunicación y Relaciones Públicas, Planner Media donde analizaron 3000 piezas de opinión, solo el 21\% de las mismas estaban escritas por mujeres.

Este dato revela una evidente infrarrepresentación de las profesionales en la sección de opinión lo cual implica que el control del discurso público en este ámbito y, por ende, la opinión dominante sea la de los hombres. La capacidad de impacto social y la responsabilidad que recae sobre los/las profesionales de los MMCC 
en la creación de imaginarios colectivos deben tener presente el riesgo de caer en un sesgo androcéntrico al narrar la realidad.

En este intento por detectar y examinar los elementos de poder y desigualdad que se transmiten en el lenguaje y componen los discursos se han seleccionado 6 artículos a modo de ejemplo de lo que posteriormente se hará con las piezas recopiladas para este estudio.

\section{I.I. Corpus}

La breve muestra de artículos analizados para esta ejemplificación es la siguiente:

- Cayetana Álvarez de Toledo: "No a la guerra" (El Mundo, 8 de marzo de 2018).

- Federico Jiménez Losantos: "Femicomunismo" (A) (El Mundo, 5 de marzo de 2018) y "Que salga Tania" (B) (El Mundo, 7 de marzo de 2018).

- J. Rodríguez: "Sin novedad en casa, cariño" (Deia, 9 de marzo de 2018).

- Félix de Azúa: "Burradas" (El País, 13 de febrero de 2018).

- Poirier, Agnès:" Deneuve y el feminismo de las francesas" (El País, 22 de enero de 208).

\section{I.2. Estrategias}

Las tres estrategias (o premisas) ${ }^{2}$ aplicadas en el análisis de estos artículos de opinión son:

1. Tratar como "anómalo", "irracional", "infantil", o, simplemente, falto de lógica el argumento que no reproduce, acepta o comparte lo que estos autores piensan.

2. Desvirtuar el debate acerca del feminismo con exageraciones, imprecisiones y caracterizaciones que perpetúan los tópicos.

3. Sustituir los argumentos elaborados por expresiones y prácticas lingüísticas que denigran a las mujeres y reproducen estereotipos sexistas.

${ }^{2}$ Estas estrategias (o premisas) fueron diseñadas por la investigadora María Pilar Rodríguez Pérez (Universidad de Deusto) para una comunicación presentada bajo el título «Resistencias al movimiento \#MeToo: respuestas en la prensa española de opinión al manifiesto de intelectuales francesas». 


\section{I.3. Ejemplo ACD}

1. Tratar como "anómalo", "irracional", "infantil", o, simplemente, falto de lógica el argumento que no reproduce, acepta o comparte lo que estos autores piensan.

La asimetría de poder también puede presentarse en forma de relaciones discursivas. El lenguaje $y$, por tanto, el discurso, es poder y en el caso que nos atañe recae sobre una élite. Esta élite está conformada por profesionales acreditados del mundo de la comunicación donde su puesto les asegura el control social del discurso, así como un amplio sector de la sociedad como audiencia. Desde esta posición de dominio de los recursos podrán ejercer un control discursivo de los actos lingüísticos mediante la persuasión como forma de ejercer el poder (Chomsky y Herman, 1988). De este modo, serán capaces de trasmitir su propio ideario, adjetivando la realidad de un modo afín a sus propias creencias.

Hace ya unos años que el movimiento feminista empezó a derrapar hacia un victimismo pueril, puritano y paralizante. Su retórica es puro helio inyectado en la realidad (...) Digámoslo sobriamente: para ser una mujer no hace falta actuar como un hombre. Ni tampocollorar como un bebé(...) Nada hay más paralizante, contrario al pleno despliegue del potencial de una mujer, que el victimismo. Y nada más peligroso para la convivencia y la salud democráticas. El victimismo es uno de los peores vicios de nuestro tiempo. Está vinculado a la infantilización del mundo contemporáneo y su principal efecto político es el populismo. Para un demagogo de medio pelo o coleta el paraíso son millones de víctimas necesitadas de un salvador. Sí, de un macho. Y bien alfa. (Álvarez de Toledo)

Por otro lado, y entre las personas que no secundan la filosofía feminista podrían estar aquellas que justifican su rechazo por la identificación del movimiento con las feministas radicales de la segunda ola y además reconocen en el mismo, problemas de imagen.

Parodiando a Stleg Larsson, diríase que las femicomunistas de cartilla son mujeres que odian a las mujeres, a las reales, que ni aceptan su sexismo, ni odian a todos los hombres, ni van a dejar de cuidar a sus madres un día porque ellas lo manden. ¡Y mira que les gusta mandar! (Jiménez Losantos /A)

Si en lugar de leer libros feministas leyera un poco de literatura habría podido elegir otra palabra, "portavocisa", que no habría levantado la menor suspicacia. ¿ No tenemos poetisa y sacerdotisa? Pues portavocisa sería un palabro estupendo. (Azúa)

2. Desvirtuar el debate acerca del feminismo con exageraciones, imprecisiones y caracterizaciones que perpetúan los tópicos.

Los MMCC son agentes de dos procesos: identitarios y de legitimación. Por un lado, generadores de subjetividad e inter-subjetividad ya que los procesos identitarios 
requieren del reconocimiento propio y de los demás. Y por otro, constituyentes de un espacio de legitimación social y simbólica puesto que son transmisores de valores, ideas y normas de conducta. Por lo tanto, el proceso de aceptación social será más idónea cuando la adhesión a una etiqueta determinada me facilite la pertenencia al grupo. En la creación del imaginario colectivo que envuelve al movimiento feminista estarán inmersos los MMCC.

La murga retrofeminista sería reducible a un bongo más de la orquesta antisistema si no tuviera consecuencias. $Y$ si esas consecuencias no fueran tan negativas: el victimismo y la guerra de sexos. Como proclama el manifiesto que un grupo de mujeres presentamos anteayer, no nacemos víctimas. Y sobre todo no lo hacemos en España. (Álvarez de Toledo)

Hacía mucho tiempo que no se proponía como banderín de enganche para una huelga general de la mitad de la humanidad sita en España (nada menos) un texto tan grotesco, tan contrario a la Historia, la Gramática, el sentido común y el sentir general de las mujeres como el que alguna célula femicomunista ha alumbrado para el día 8 de marzo, homoheterotranshuelga a la que se ha sumado el arzobispo de Madrid en nombre de la Virgen María (...) El femicomunismo habla, teóricamente, en nombre de todas las mujeres, pero va en contra de lo que hace y dice la mayoría de las mujeres reales. (Jiménez Losantos /A)

En los últimos 20 años, aproximadamente, ha surgido un nuevo feminismo francés, importado de Estados Unidos, que ha adoptado esa paranoia antimasculina que describía Beauvoir y que nos es bastante ajena. Se ha apoderado de \#MeToo en Francia y se ha manifestado ruidosamente contra la carta encabezada por Deneuve. (Poirier)

3. Sustituir los argumentos elaborados por expresiones y prácticas lingüísticas que denigran a las mujeres y reproducen estereotipos sexistas.

Puede ser que durante algunos años los MMCC hayan trasmitido un tramposo ideario feminista/ post-feminista en torno al papel de la mujer. Parece que, al menos en la ficción, las mujeres hubieran alcanzado la igualdad. Esta corriente, si bien pudo haber calado en el entorno mediático y, por ende, en parte del imaginario social no así ha sido en el ámbito académico donde sus detractores/as han sido mayoría. En el argumentario producido por algunos/as periodistas, puede apreciarse dicha ideología y cierta intención de denigrar a la mujer y a su lucha.

Casos de mujeres asesinadas o agredidas son exhibidos como prueba de la violencia intrínseca del hombre y del sistema. Se obvia la posibilidad de que las mujeres queramos trabajar a tiempo parcial, como en la hiperigualitarista Holanda. Las estadísticas se inflan hasta pintar un infierno labora, de mujeres explotadas y humilladas por sus jefes y colegas. ¿̇Y total para qué? La exageración no impulsa el progreso (...). Esta huelga no es a favor de la mujer, sino en contra del hombre. "iNo, no!", bramarán. Pero, a ver, ¿̇contra quién si no protestan? ¿Quién es el culpable de la discriminación? Si no es la Virgen María, será San José. Y eso que, en su caso, no hubo ni mano en la rodilla. 
A falta de enemigos reales, el nuevo feminismo ha decidido librar una guerra contra un espectro. Weinstein es un hombre raro entre los hombres, porque, jincluso entre los hombres!, lo raro es ser un criminal. Un piropo no es una agresión sexual. Y los sentimientos no son hechos. Esto último lo digo por la encuesta de El País según la cual un tercio de las mujeres españolas se ha "sentido" acosada alguna vez (...) A nadie le interesa una guerra de sexos. Y desde luego no nos interesa a las mujeres. Primero, porque la fuerza no es nuestro fuerte. Salvo que consigamos emascular a nuestros enemigos, hacerlos a todos peluditos y suaves como un Platero metrosexual. (Álvarez de Toledo)

Digo relevantes por su trayectoria profesional de muchas décadas, no por llevar dos años en un puesto destacado pero dependiente del Macho Alfa (refiriéndose a Irene Montero), que es quien pone cargos y reparte cargas (...). "Será muy difícil que se visibilice en el Congreso que hay mujeres que estamos haciendo huelga y parando", dijo la diputada, que espero no cobre el tiempo que no trabaja, porque todos le pagamos el sueldo para que trabaje. Para montar numeritos, a la calle y en domingo (...) ¿ Quiere Montero que se visibilice a las huelguistas de la bancada que pastorea? Es fácil: que salga Tania Sánchez de detrás de la columna. No al burka de estuco. No al cobrador de Teherán. (Jiménez Losantos /B)

ESTIMADA cariño mío. Ayer te vi en el informativo de la noche bañándote en la Plaza Moyua con unas amigas y supuse que llegarías a casa tarde después de ese día tan reivindicativo del que disfrutaste. Te dejo esta nota para informarte de que todo ha ido bien. Llevé a los niños al colegio sin desayunar porque no encontré el Cola Cao, pero les compré pistachos en un chino. Por cierto, jno me habías dicho que les habíamos cambiado de centro! (...) Me telefoneó una señora al trabajo cuando se la encontró en la cama. ¿Quién es y por qué tiene llave de nuestro piso? ¿Quizá tu madre o una interina? Si no es así, tenemos que llamar a la Ertzaintza y cambiar la cerradura (...). Al final, cenamos pepinillos con donuts, y la niña, que es muy simpática cuando coge confianza, se puso mala. Para que le bajara la fiebre, le di unas pastillas de la marca Lacasitos que había en el botiquín. Bueno, a la noche hablamos. Ya no hacéis más huelgas hasta el año que viene ¿verdad? Es para organizarme un poco. Un beso. (Rodríguez)

Al aplicar estos tres criterio o estrategias de análisis a la muestra de artículos seleccionada pueden apreciarse ciertas resistencias generadas ante el avance del movimiento feminista. Las reacciones negativas a este repunte del feminismo se muestran en una abierta y declarada reticencia a simpatizar con el movimiento. Además, este crítico posicionamiento vendrá siendo definido en este caso por los/ as profesionales medios, autores/as de estos artículos, los/as cuales pertenecen a un grupo privilegiado. Así pues, se dará un ejemplo más donde la élite detenta el poder discursivo. 


\section{Conclusiones}

Citando de nuevo a van Dijk (1996, p. 84-85), el poder se expresa, reproduce y legitima a través del lenguaje. Es a partir de aquí desde donde se construirán modelos mentales personales de los acontecimientos. Por ende, y como defiende Castells, los MMCC construyen y reproducen el poder y por eso desde ellos es posible aceptar, cuestionar o rechazar el statu quo hegemónico. Por otro lado, también recaerá sobre la audiencia la responsabilidad de sanear el discurso público ya que este imaginario se construye a través de la interacción individual.

Ante esta responsabilidad dual de los MMCC y la sociedad, se ha fraguado la razón de ser de esta investigación desde la que se pretenderá averiguar cómo se emite/ recibe el mensaje sobre el feminismo para comprender el imaginario construido alrededor de este controvertido concepto. Como decía Karl Marx "lo concreto es concreto porque es la síntesis de múltiples determinaciones" (Marx, 2007, p. 24). Con esta reflexión quería defender la idea de que la explicación profunda de un fenómeno no deriva de sus atributos superficiales sino de sus raíces y estructuras, así como de diversos factores, que son los que configuran la realidad que percibimos.

En este punto, el feminismo será un movimiento comprometido con la reconstrucción de la identidad de la mujer (Castells, 1996). Como sujeto social tendrá un papel destacado en la gestión de la acción colectiva que se moviliza por este cambio cultural, de valores, actitudes y principios, además de ser un agente de producción de información y signos culturales (Melucci, 2001).

Al feminismo, le precedieron décadas en los que adherirse esta etiqueta resultaba poco frecuente e incómodo. Ahora las rutinas periodísticas y la cultura popular parecen acoger con renovado entusiasmo el interés por esta doctrina. En unos tiempos en los que el feminismo es tendencia, se tendrá presente la peligrosa inercia que tendría caer en un feminismo vacuo o banal en el intento de este movimiento social por hacerse universal y tratar de reclutar el máximo número de personas posibles. Simplificar el mensaje del feminismo puede ser un arma de doble filo que conviene analizar.

Ante esta realidad conviene ser exigentes con lo que como espectadores/as consumimos ya que lo que podría ser una cínica estrategia de marketing 0 , por el contrario, una apología disuasoria del movimiento, estaría enviando un mensaje distorsionado.

Y es ahora, en este contexto, de aparentes grandes oportunidades para el movimiento feminista, cuando este debe tener la capacidad reflexiva oportuna para 
dar viabilidad a sus reivindicaciones y estrategias lo cual nunca será posible sin, lo que Inglehart (1992) acuñó como, una movilización cognitiva de la sociedad.

Así pues, la finalidad última de esta investigación será aportar reflexión teórica al feminismo, así como generar apoyo empírico al debate actual. En este proceso se tendrá presente la idiosincrasia propia de la Comunidad Autónoma de Euskadi, demarcación geográfica de la muestra del estudio de percepción social sobre feminismo.

Cerramos recordando la acertada reflexión de Amelia Valcárcel, "del feminismo siempre se dice que es un recién nacido y que ya está muerto" (citado en Varela, 2013 , p. 14) ... quedando expectantes ante lo que depare esta ola de posibles cambios.

\section{Referencias}

Altés, E.; Bach, M.; Gallego, J.; Plujà, M. y Puig, M. (2000) El sexo de la noticia, Barcelona: Icaria.

Bauman, Z. (1999) Modernindad líquida. Acerca de lo leve y lo líquido, Buenos Aires, Fondo de Cultura Económica.

Bolx, M. (2002) «Feminismos, comunicación y tecnologías de la información. El periódico feminista: Mujeres en Red». Recuperado de: http://www.mujeresenred. $\mathrm{net} / \mathrm{m}$ _boix-feminismo_y_comunicacion.html [consultado el 08-05-2018].

BUtLER, J. (1990) Gender trouble, Londres: Routledge.

CACACE, M. (2006) Mujeres jóvenes y feminismo: valores, cultura y comportamientos frente a frente, Madrid: Narcea.

CARTER, J. (Ed.) (2012) Postmodernity and the fragmentation of welfare, Londres: Routledge.

CAstell, M. (1996) La era de la información. El poder de la identidad, vol. 2, 159-269, Alianza Editorial.

- (2009) Communication Power, Oxford y Nueva York, Oxford UP. 
Chomsky, N. y Herman, E. S, (1988) Los guardianes de la libertad (título original, en inglés, Manufacturing Consent: The Political Economy of the Mass Media) (1 ${ }^{a}$ edición), Barcelona: Crítica.

DOUGLAS, S. J. (1994) Where the girls are: Growing up female with the mass media, Nueva York: Times Books.

FACIO, A. (1999). «Feminismo, género y patriarcado: Lectura de Apoyo» 1. Recuperado de: http://justiciaygenero.org.mx/wp-content/uploads/2015/04/ Feminismo-género-ypatriarcado.-Alda-Facio.pdf

FALUDI, S. (1991) Backlash the undeclared war against American women, Nueva York: Crown Publishers.

Foucault, M. (1983) «The subject and power: Afterword》, en DreYFus, H. L. y RaBinOw, R. (Eds.), Michel Foucault (2 ${ }^{a}$ ed.), (pp. 208-227), Chicago: University of Chicago Press.

Freedman, J. (2001) Feminism, Philadelphia: Open University Press.

HASMATH, R. (2014) «The discursive construction and performance of gendered identity on social media». Recuperado de: http://works.bepress.com/rhasmath/24

Hooks, B. (2000) Feminism is for everybody, Londres: South End Press.

INGLEHART, R. (1992) «Valores, ideología y movilización cognitiva en los nuevos movimientos sociales» en DALTON, R. J. y M. KUECHLER (comp. 1992): Los nuevos movimientos sociales: un reto al orden político, València: Alfons el Magnànim.

LULL, J., MULAC, A., y ROSEN, S. L. (1983) «Feminism as a predictor of mass media use», Sex Roles 9, 165-177.

MARX, K. (2007) Elementos fundamentales para la crítica de la economía política (Grundise) (1857-1858) (7), Madrid: Siglo XXI.

MelucCl, A. (1994) «Asumir un compromiso: identidad y movilización en los movimientos sociales», Zona Abierta 69.

- (2001): «¿Qué hay de nuevo en los movimientos sociales?», en LARAÑA, E. y GUSFIELD, J. (eds.): Los nuevos movimientos sociales. De la ideología a la identidad, Madrid, CIS, 119-149. 
Miletr, K. (2010) Política sexual, Madrid: Cátedra.

MONTERO, R. (2018) «Dos pasos para atrás o para adelante», El País Semanal (11-2-2018).

MoRán, E. (1998) Géneros del periodismo de opinión. Crítica, comentario, columna, editorial, Pamplona: Universidad de Navarra.

PHILLIPS, R., y CREE, V. E. (2014) «What does the 'fourth wave' mean for teaching feminism in 21 st century social work?», Social Work Education the International Journal, 1-14. doi:10.1080/02615479.2014.885007

RHODE, D. L. (1995) «Media images, feminist issues», Signs 20, 685-710.

Rossl, A. (1982) Feminists in politics, Nueva York: Academic.

SAU, V. (2000) Diccionario ideológico feminist, vol. I, Barcelona, Icaria.

SCHNeIDER, B. (1988) «Political Generations in the Contemporary Women's Movement», Sociological Inquiry 58, 4-21.

SENDÓN, V. (2000) «¿Qué es el feminismo de la diferencia?: Una visión muy personal», El periódico feminista: Mujeres en Red. Recuperado de: http://www. mujeresenred.net/IMG/article_PDF/article_a1985.pdf

Strauss, A. y CORBIN, J. (1990) Basics of qualitative research: Grounded theory procedures and techniques, Newbury Park, CA: Sage.

Swirsky, J. M. y Angelone, D. J. (2014) «Femi-Nazis and Bra Burning Crazies: A qualitative evaluation of contemporary beliefs about feminism», Current Psychology 33, 229-245.

TAffel, H. y TuRner, J. C. (1989) «La teoría de la identidad social de la conducta intergrupal», en MORALES, J. F. y HuICI, C., Lecturas de Psicología Social, pp. 225-259, Madrid: UNED. (Trabajo original publicado en 1985).

Valcárcel, A. (1991) Sexo y filosofía. Sobre "mujer" y "poder", Barcelona: Anthopos.

- (2001) La memoria colectiva y los retos del feminismo, Naciones Unidas, Chile. 
VAN DIJK, T. (1996) «Discourse, power and access》, en CALDAS-CoulthaRD C. R. y CoulthARD, M. (eds.), Texts and practices, 84-104, Londres: Routledge.

- (1999) «El análisis crítico del discurso», Anthropos 186, 23-36.

- (2003) Ideología y discurso, Barcelona: Ariel.

VAN Der BRINK, M. y BensChOP, Y. (2014) «Gender in Academic Networking: The Role of Gatekeepers in Professorial Recruitment», Journal of Management Studies $51(3), 460-492$.

VARELA, N. (2013) Feminismo para principiantes, Barcelona: Penguin Random House.

Yeung, A. W. Y., KaY, A. C. y PeACH, J. M. (2014) «Anti-feminist backlash: The role of system justification in the rejection of feminism», Group Processes \& Intergroup Relations 17(4), 474-484.

ZUCKER, A. N. (2004) «Disavowing social identities: What it means when women say, "I'm not a feminist, but..." ", Psychology of Women Quarterly 28 (4), 423-435. 